\title{
Study of the Gas Balance by Injection of Hydrocarbons into the Plasma Simulator PSI 2
}

\author{
Werner Bohmeyer ${ }^{1}$, Andrey Markin ${ }^{2}$, Bernd Koch ${ }^{1,3}$, Gordon Krenz ${ }^{3}$ and \\ Gerd Fussmann ${ }^{1,3}$ \\ ${ }^{1}$ Max-Planck-Institut für Plasmaphysik TI Greifswald, Wendelsteinstr.1 17491 Greifswald EURATOM Ass. \\ ${ }^{2}$ RAS, Institute of Physical Chemistry, Moscow \\ ${ }^{3}$ Humboldt-Universität zu Berlin, Plasmaphysik, Newtonstr.15 12489 Berline-mail: bohmeyer@ipp.mpg.de
}

\begin{abstract}
The stationary plasma of the plasma generator PSI 2 is used to study the gas balance of hydrocarbons and hydrogen by means of mass spectrometers. For this purpose $\mathrm{H}_{2}$, acetylene and ethylene are injected into argon and hydrogen plasmas. Several mono-layers of a-C:H are formed after only a few minutes of injection. It is found that hydrogenation of the hydrocarbon layers is strongly influenced by the hydrocarbon species injected previously. Furthermore, time constants of more than $1000 \mathrm{~s}$ for achieving stationary conditions are identified in some cases. The $\mathrm{H} / \mathrm{C}$ ratio of the hydrocarbon layers is found to vary from about 1 to 1.4 for argon and hydrogen plasmas, respectively.
\end{abstract}

PACS :81.05, 91.15-z, $52.40 \mathrm{Hf}$

Key words hydrocarbons, a-C:H films, deposition

\section{Introduction}

The formation of a-C:H layers on the walls of fusion devices has been identified as a crucial issue with respect to tritium storage. Depending on composition, energy of the particles striking the surface and the surface temperature, the hydrogen content in these films may vary over a wide range. The parameters determining the hydrogen storage capability will differ for the various surface regions of a device but an overall value can be estimated from the $\mathrm{H}_{2}$ input/output balance. Recent publications addressing the problem of the gas balance in current tokamaks have been reviewed by Loarer et al. [1].

In this paper we apply quadruple mass spectrometry to analyse the neutral gas composition in the plasma chamber and in the exhaust channel of the PSI 2 plasma generator. One of our aims is to estimate the hydrogen content in a-C:H films growing on the walls when injecting hydrocarbons into argon or hydrogen plasmas. In addition the processes involved in layer formation and the characteristic times for attaining stationary conditions are of interest.

\section{Experiment}

PSI 2 is a stationary operated facility using a high current arc discharge in an axial magnetic field for the generation of a dense plasma. The plasma is produced between a heated $\mathrm{LaB}_{6}$ cathode and a hollow molybdenum-anode. After passing a pumping stage the quasi neutral, current free plasma $(\phi \approx 8 \mathrm{~cm})$ reaches the target chamber of about $1.5 \mathrm{~m}$ in length.. At its end the plasma is neutralized at a water cooled tungsten plate. By means of several turbo-pumps a base pressure of less than $10^{-5} \mathrm{~Pa}$ is attained in the device. During a discharge the working gas is blown in at the cathode and the pressure in the anode-cathode region increases up to $1 \mathrm{~Pa}$ whereas in the target chamber it varies between 0.1 to $1 \mathrm{~Pa}$ depending on the number of turbopumps being used. The magnetic field strength in the target chamber is about $0.1 \mathrm{~T}$. One differentially pumped quadrupole mass spectrometer (QMS1, type Prisma 200) is connected to the target chamber. This analyzer is equipped with a conventional "open ion source". The typical inside pressure during plasma operation is around $10^{-5} \mathrm{~Pa}$; a quantitative analysis is therefore possible for both, working gas and impurities. The second analyzer (QMS2, type SPM-200) is mounted between the turbo-pumps and the fore-vacuum pump where the pressure is in the range of $1 \mathrm{~Pa}$. Being equipped with a closed type ion source it allows a semiquantitative analysis of small impurity amounts in the exhaust while the detection of the main component (Ar or $\mathrm{H})$ is not possible. 


\section{Results and discussion}

From earlier experiments [2] it is known that the degree of decomposition of the injected $\mathrm{C}_{\mathrm{x}} \mathrm{H}_{\mathrm{y}}$ molecules strongly depends on electron density. Nevertheless, the threshold density for decomposition is relatively low. In Fig. 1 an example for methane $\left(\mathrm{CH}_{4}\right)$ injection into an argon plasma is shown. The concentrations of $\mathrm{CH}_{4}$ and $\mathrm{H}_{2}$ are plotted versus plasma current. The electron density trace is also given in the figure.



Figure 1: Decomposition of $1 \mathrm{sccm}$ methane injected into an argon discharge (QMS 1).



Figure 2. Temporal evolution of $\mathrm{H}_{2}$ concentration in the exhaust channel as measured by QMS2 in the case of $\mathrm{C}_{2} \mathrm{H}_{2}$ and $\mathrm{H}_{2}$ injection into an Ar plasma (100A).

From our previous investigations [2] it could also be inferred that practically all carbon atoms injected into the plasma chamber, either as ethylene $\left(\mathrm{C}_{2} \mathrm{H}_{4}\right)$ or $\mathrm{CH}_{4}$, are retained inside the vessel, most likely bound in a-C:H layers on the inner walls of vessel.

We first used $\mathrm{C}_{2} \mathrm{H}_{2}$ (acetylene) having the benefit that the same amount of carbon and hydrogen is injected. Consequently, we expect a relatively weak variation of the hydrogen concentration in the exhaust. The temporal evolution of $\mathrm{H}_{2}$ (mass 2 signal) recorded by QMS2 in the exhaust is shown in Fig. 2 when injecting $0.5 \mathrm{sccm} \mathrm{C}_{2} \mathrm{H}_{2}$ into an Ar plasma $(2150 \leq \mathrm{t} \leq 2350$ s). Injecting the same amount of $\mathrm{H}_{2}$ without plasma $(3800 \leq \mathrm{t} \leq 3950 \mathrm{~s})$ allows calibration of the signal. By comparing the signals during the various time intervals we learn that only a small fraction of the injected $\mathrm{C}_{2} \mathrm{H}_{2}$ molecules is converted to $\mathrm{H}_{2}$ and pumped off. This is in agreement with the expectations and the assumption of a ratio of $\mathrm{H} / \mathrm{C} \approx 1$ for the layers. After a period without injection, $0.5 \mathrm{sccm} \mathrm{H}_{2}$ were injected again, this time during the plasma phase $(\mathrm{t}=4300 \mathrm{~s})$. The slow rise of the hydrogen concentration in the exhaust indicates an effective trapping of hydrogen in the target chamber. It can be explained by hydrogenation of the a-C:H layers grown during the preceding acetylene decomposition phase. This means that by hydrogen injection into an argon plasma the a-C:H layers become enriched with hydrogen. For long $\mathrm{H}_{2}$ injection periods or in case of stationary hydrogen discharges we therefore expect $\mathrm{H} / \mathrm{C}$ ratios larger than 1.

In an attempt to produce such hydrogen enriched layers by hydrocarbon injection we injected $0.5 \mathrm{sccm}$ of $\mathrm{C}_{2} \mathrm{H}_{4}$ (ethylene) the molecules of which carry twice as much $\mathrm{H}$ atoms as acetylene or $\mathrm{H}_{2}$. The result is shown in Fig. 3. We first notice, that the hydrogen concentration measured during the initial phase $(\mathrm{t}=0-200 \mathrm{~s})$ in the exhaust is about half the concentration found during the $\mathrm{H}_{2}$ calibration phase $(\mathrm{t}=1550-1650 \mathrm{~s})$, where this time twice the amount is injected ( $1 \mathrm{sccm} \mathrm{H}_{2}$, i.e. the same number of $\mathrm{H}$ atoms as in the ethylene pulse). 


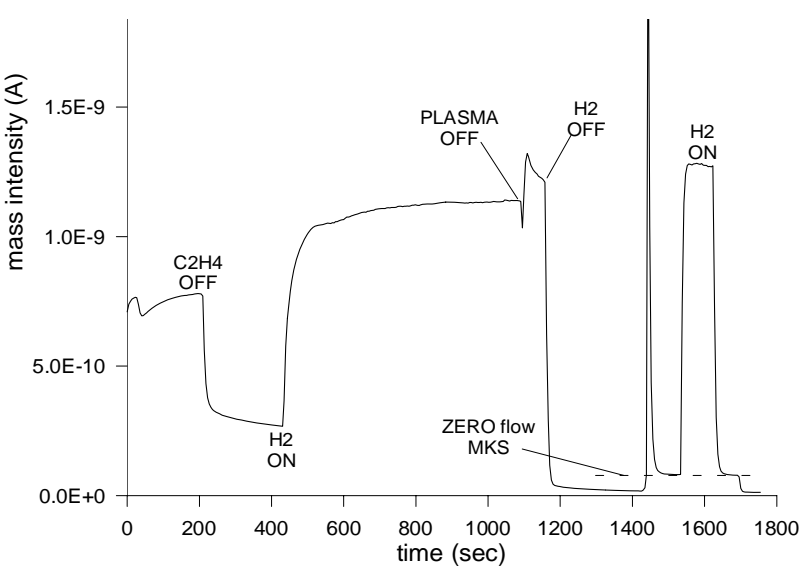

Figure 3. Temporal evolution of $\mathrm{H}_{2}$ in case of $\mathrm{C}_{2} \mathrm{H}_{4}$ injection. Argon discharge $100 \mathrm{~A}$ (QMS 2).



Figure 4: Temporal evolution of $\mathrm{H}_{2}$ in the exhaust line after $\mathrm{H}_{2}$ injection into an Ar discharge (100 A): (1) pure argon plasma, (2) injection of hydrogen, and (3) hydrogen injection without plasma. (QMS2)

term hydrogen trapping is observed: immediately after injection $(\mathrm{t}=1550 \mathrm{~s})$ the signal reaches the plateau value. Presumably, the films deposited from $\mathrm{C}_{2} \mathrm{H}_{4}$ decomposition are less susceptible to hydrogenation as those from $\mathrm{C}_{2} \mathrm{H}_{2}$ although both contain nearly the same amount of hydrogen.

In order to assess the time constants involved in hydrogenation we continuously injected hydrogen after long term Ar plasma conditioning. The result is shown in Fig. 4. It is seen that there is a significant loss of the injected hydrogen during the first $1000 \mathrm{~s}$. After saturation of the $\mathrm{H}_{2}$ exhaust signal (level 2) the plasma is switched off $(\mathrm{t}=9250 \mathrm{~s})$, resulting in an considerable enhancement of the signal. The stationary level 3 , however, indicates that there is a long term loss of the injected hydrogen. Obviously, the hydrogenation process is continuously going on for more than 1000 s.

The amount of hydrogen retained during the initial phase (hatched area) is estimated to be sufficient for the hydrogenation of the topmost 1-2 nm layer on the chamber walls from initially $\mathrm{H} / \mathrm{C}<<1$ to about $\mathrm{H} / \mathrm{C} \approx 1$ during saturation (in agreement with findings reported in [3]).

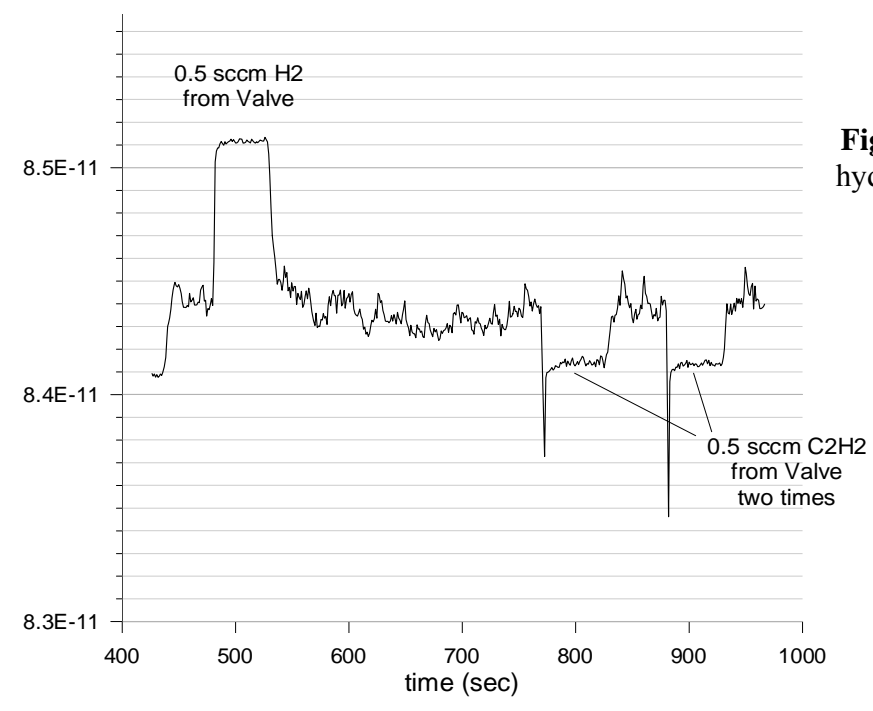

Figure 5: Temporal evolution of the $\mathrm{H}_{2}$ signal (QMS1) for hydrogen and $\mathrm{C}_{2} \mathrm{H}_{2}$ injection into a hydrogen discharge. 
Similar experiments have been performed in the case of hydrogen plasmas. Results are shown in Fig. 5. For the purpose of calibration, a hydrogen pulse of $0.5 \mathrm{sccm}$ was added at $\mathrm{t}=500 \mathrm{~s}$. Interestingly, the injection of $\mathrm{C}_{2} \mathrm{H}_{2}$ (starting at $\mathrm{t}=800$ and $900 \mathrm{~s}$ ) is seen to induce a reduction of the $\mathrm{H}_{2}$ concentration in the plasma chamber. This indicates that the chemical activity of the layers is enhanced by the addition of $\mathrm{C}_{2} \mathrm{H}_{2}$, i.e. during the $\mathrm{C}_{2} \mathrm{H}_{2}$ injection phase they are able to absorb considerably more atomic hydrogen than previously. In other words: during the $\mathrm{C}_{2} \mathrm{H}_{2}$ injection the walls act as an additional pump and layers with $\mathrm{H} / \mathrm{C}$ ratios distinctly larger than 1 are produced. It should be mentioned that in case of $\mathrm{C}_{2} \mathrm{H}_{4}$ injection a different behaviour is observed. This time the $\mathrm{H}_{2}$ concentrations are seen to rise during injection. Nevertheless, an enhanced activation of the layers may take place also in this case but does not lead to a reduction of the $\mathrm{H}_{2}$ concentration because the number of injected $\mathrm{H}$-atoms is doubled. Finally, by means of the calibration pulse the $\mathrm{H} / \mathrm{C}$ ratio for the non-injection phase could be estimated to $1.4 \pm 0.1$; this may be considered as a typical value attained in hydrogen discharges.

\section{Summary}

Although the fusion community is most interested in plasma wall processes pertinent to hydrogen plasmas we found it quite instructive to go ahead with some injection experiments in argon. From those we learnt that, when blowing $\mathrm{H}_{2}$ into a long conditioned Ar plasma, a considerable fraction of the $\mathrm{H}$ atoms is retained inside the device and used for hydrogenation of the top-most hydrocarbon layers on the walls. In particular during the first $1000 \mathrm{~s}$ after injection a marked hydrogen enrichment is taking place, changing the $\mathrm{H} / \mathrm{C}$ ratio from low initial values to about 1 . This result will be relevant for some ITER scenarios, when $\mathrm{H}$-deficit layers are produced as a consequence of ELM instabilities or disruption events.

There are notable differences observed in the temporal response when blowing either $\mathrm{H}_{2}$, $\mathrm{C}_{2} \mathrm{H}_{2}$ or $\mathrm{C}_{2} \mathrm{H}_{4}$ into argon discharges with saturated hydrocarbon layers $(\mathrm{H} / \mathrm{C} \approx 1)$. While in most cases a prompt reaction is observed, rise times of several $100 \mathrm{~s}$ second were found in case of $\mathrm{H}_{2}$ injection when the layers were produced by preceding $\mathrm{C}_{2} \mathrm{H}_{2}$ injection.

Based on the experience and knowledge gained from argon discharges it was possible to understand some observations made in hydrogen plasmas. Here, in particular, it was found that hydrogenation of the hydrocarbon layers is strongly influenced by the hydrocarbon species injected previously: When blowing $\mathrm{C}_{2} \mathrm{H}_{4}$ into the hydrogen plasma the hydrogen concentration is increased in the plasma chamber as well as in the exhaust line. In contrast, both concentration decrease in the case of $\mathrm{C}_{2} \mathrm{H}_{2}$ injection. The latter fact is interpreted by an enhanced chemical activity of the wall which is then able to absorb more hydrogen atoms. Finally, the $\mathrm{H} / \mathrm{C}$ ratio of saturated hydrocarbon layers in case of hydrogen plasmas could be determined to $1.4 \pm 0.1$.

This work has been carried out within the research program of the European Task Force on Plasma Wall Interaction and was partially supported by TWR-TVM-CFC2.

\section{REFERENCES}

[1] T. Loarer , J.Bucalossi, G. Matthew, V. Phillips, JET -EFDA Collaborators, Journal of Nucl. Mat. 337-339 (2005) 624-628

[2] W. Bohmeyer, D. Naujoks, A. Markin, B. Koch, D. Schröder and G. Fussmann, Transport and Deposition of Injected Hydrocarbons in Plasma Generator PSI-2, PSI-16, J.Nucl.Mat. 337-339 (2005) 89-93

[3] A. von Keudell, W. Jacob, J. Appl.Phys 79, (1996), 1092 